\title{
Memorial Luiz Camillo
}

\section{Marco Antônio Tavares Coelho}

A O SE Resenhar um livro como Luiz Camillo, análises diferenciadas aparecem porque estamos diante de uma obra literária que ficará como uma referência na memorialística brasileira. Portanto, vários ângulos podem ser examinados sobre esse meticuloso estudo focalizando uma personalidade singular na vida nacional.

Vejamos, inicialmente, o arcabouço do livro, as soluções encontradas pela autora, Maria Luiza Penna, para apresentar Luiz Camillo, quase um ilustre desconhecido mesmo para os que acompanharam em décadas passadas nossa vida política e cultural. Hoje, Luiz Camillo paira no meio dos arquivos que tanto amava, embora seja reverenciado por um conterrâneo de Itabira, que proclamou: "Todos nós, que o conhecemos mais de perto, temos alguma dívida, de afeição ou de civismo, para com o admirável Luiz Camillo" - Carlos Drummond de Andrade (p.29).

Afirmação singela e precisa, que só os poetas sabem fazer, mas que me levam a recordar, num desvão da memória, a única vez que, acompanhado de Darcy Ribeiro, fui a um encontro com Luiz Camillo. O fato ocorreu em 1943, quando da realização de um Congresso Nacional de Estudantes, no Rio de Janeiro. ${ }^{1}$ E o saldo daquela conversa foi precisamente uma dívida de civismo que contraí com ele. Porque, embora discordando de sua catequese, fiquei extasiado diante da manifestação inteligente, arguta e candente daquele que diuturnamente conspirava pelo fim do "Estado Novo".

Examinando a estrutura desse livro, depreendo as dificuldades da montagem desse "perfil intelectual". Luiz Camillo não chegou a ser um prócer de primeira grandeza no mundo político, ou uma figura de prol na galeria dos "imortais" da literatura ou da historiografia. Em razão disso, deixou para a posteridade apenas algumas provas do impacto de sua presença nos círculos políticos e culturais, naquela fase tão cheia de incongruências em nosso país.

O registro de sua vida, portanto, está limitado a artigos esporádicos, a relatórios esparsos dando conta de suas pelejas nos entreveros na burocracia, além de entrevistas dos que com ele conviveram. Maria Luiza Penna, embora tenha manifestado reservas sobre o uso de cartas num trabalho historiográfico, apoiou-se também na vasta correspondência de seu pai, documentação essencial para reconstituir o cenário e o desempenho de Luiz Camillo. Esse dado é reconhecido por sua filha ao afirmar haver costurado o seu texto com "citações dessas cartas, talvez a parte mais duradoura dos seus escritos, porque ali ele manifestou seu pensamento, e sua visão do mundo..." (p.33).

Sua filha praticamente retirou do ostracismo um protagonista que teve uma atuação decisiva em vários episódios políticos e em certos confrontos culturais em nossa pátria, na fase que vai do movimento de 1930 aos idos de 1950. Por isso, ela trabalhou como um paleontólogo, que junta pedaços de um vivente em outras eras para erguer uma estrutura de imensa dimensão. Apoiada em lembranças familiares e na pesquisa do volumoso acervo reunido por uma pessoa que amava os arquivos, a autora entregou ao país um memorial de inestimável valor. 
Examinando o método, usado com maestria e paciência por Maria Luiza Penna, penso que as dificuldades que enfrentou a levaram a inovar nossa memorialística. Complementando as pesquisas sobre o biografado, recorreu a um vasto material - considerações subjacentes, documentos e anexos - que, além de comprovar as informações aduzidas no texto, agrega fatos e dados que não poderiam ser omitidos. Contudo, o resultado de tudo isso - 650 páginas - não criou uma dificuldade intransponível a pessoas não habituadas à leitura de textos mais densos. Não. Isso porque a linguagem escorreita e a extraordinária beleza da obra gráfica muito contribuíram para a produção de um livro que incita o leitor a continuar desvendando a vida e as angústias de Luiz Camillo. (Aqui, merece um elogio pleno o trabalho da equipe que realizou uma obra esteticamente perfeita, desde a seleção de gravuras e de ilustrações até os mínimos detalhes de um trabalho gráfico antológico.)

Luiz Camillo, apresentado tão-só como um "perfil intelectual", dá uma contribuição valiosa para o entendimento da vida política e cultural em nosso país durante as décadas de 20 a 70 do século passado. No entanto, revela igualmente a dedicação incansável desse itabirano para a preservação da memória nacional, de seu estudo e de sua divulgação, trabalho desenvolvido na Casa de Rui Barbosa (1934-1938), nas pesquisas realizadas em 1937 em Portugal, como catedrático de História do Brasil na Universidade do Distrito Federal, e, após 1940, até sua morte, em inúmeras funções no Serviço de Documentação do Itamaraty.

Deixando, porém, aos historiadores a apreciação dessa atividade durante dezenas de anos, aqui destaco o que conside- ro ser a lição mais preciosa do livro. Entendo que ele é de indiscutível relevância para a compreensão da vida política brasileira de 1930 até a década de 1950. Duas razões alicerçam esse juízo: primeiro, porque esse livro elucida um período em que houve inúmeros acontecimentos de difícil explicação e com reviravoltas surpreendentes; em segundo lugar, porque a respeito dessa fase há uma exuberância de opiniões descabidas, muitas delas apoiadas apenas em preconceitos e nos desejos de sicrano ou beltrano.

Luiz Camillo não apresenta uma análise global e crítica dessa quadra de nossa história, porque os propósitos e os limites do livro foram bem grifados por sua autora. Repito - ele tão-só fornece indicações e informações que auxiliam os que desejam desnovelar o imbróglio da política brasileira naquela fase.

Um exemplo dessa contribuição é o esclarecimento de um episódio calamitoso e de profundas conseqüências para o Brasil - a destruição insensata da Universidade do Distrito Federal em 1939. Vejamos o acontecido.

Desde a Independência, a questão educacional sempre foi um tema prioritário na vida política, mesmo porque invariavelmente se badalou a necessidade da superação de erros calamitosos na formação de nossos jovens. Essa cantilena continuou até que, na década de 1920, surgiu um movimento colocando efetivamente as bases de uma renovação profunda na educação. Esses princípios foram sintetizados no Manifesto da Escola Nova, redigido por Fernando de Azevedo, defendendo que a escola pública deveria ser reformulada de conformidade com os seguintes princípios republicanos - ser gratuita, obrigatória e leiga. Tal ideário, entretanto, enfrentou a oposição da Igreja 


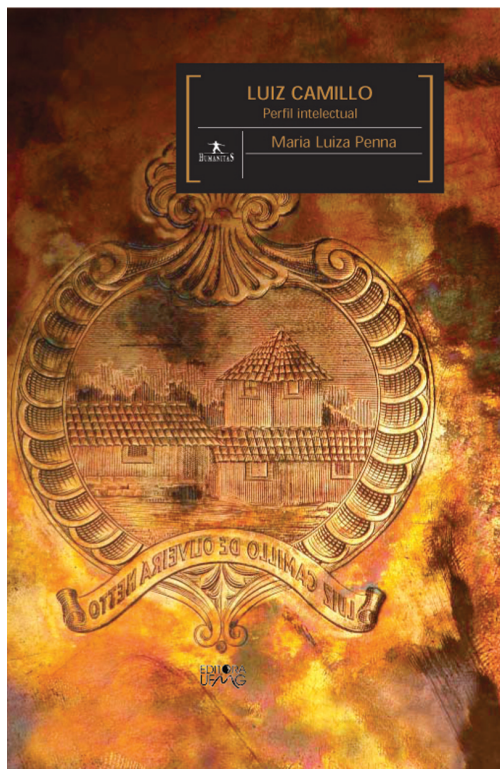

PENNA, M. L. Luiz Camillo-Perfil intelectual. Belo Horizonte: UFMG, 2006. 708 p.

Católica, porque essa desejava preservar a todo custo a prevalência de seu credo religioso na população e porque dominava quase totalmente o sistema educacional, com suas escolas confessionais pagas.

Então, talvez até como uma das conseqüências da Revolução de 1930, a luta pela Escola Nova ganhou maior força e profundidade. Assim, logo ocorreu o episódio mais dramático desse conflito quando, em 1935, idealizada por Anísio Teixeira, foi inaugurada a Universidade do Distrito Federal (UDF) (Rio de Janeiro), cuja orientação pedagógica preconizava a articulação entre ensino e pesquisa e possuía como principal objetivo a formação de professores.

Mas com a radicalização política na época e quando o governo federal era dominado por teses conservadoras e influenciado pela onda nazi-fascista, essa nova instituição acadêmica foi considerada um instrumento a serviço do proseli- tismo dos comunistas. Ademais, além de contrariar o projeto do "Estado Novo" e de Gustavo Capanema de criar uma universidade nos moldes de nossas velhas escolas superiores, a UDF recebeu o acirrado combate da hierarquia católica porque essa não podia tolerar no Rio de Janeiro uma instituição universitária declaradamente laica. Nesse quadro adverso, duas figuras de larga projeção social - Sobral Pinto e Alceu Amoroso Lima (Tristão de Athaide) - levaram o governo Vargas a liquidar a UDF, não obstante ser dirigida por um grupo de eminentes figuras, como o mineiro José Baeta Viana (o pioneiro das pesquisas de bioquímica no Brasil), Luiz Camillo, Mário de Andrade, Cecília Meireles, Luis Freire, Cândido Portinari e outros expoentes da intelectualidade.

Relata Maria Luiza Penna: "A nomeação de Luiz Camillo para a UDF muda radicalmente sua vida". Cansado do trabalho burocrático na Casa de Rui Barbosa, em 1936 aceita o convite para ministrar aulas de História na instituição que fora montada seguindo os mesmos princípios da Universidade de São Paulo (USP). Dois anos depois, quando Baeta Viana assume a reitoria, Luiz Camillo foi nomeado vice-reitor.

E assim começou o seu calvário, porque assumiu a defesa intransigente da causa da UDF, enfrentando corajosamente Francisco Campos (o escriba da "Polaca" - a Carta Constitucional do "Estado Novo" - e do Ato Institucional de 1964) e o oportunismo servil de seu ex-amigo Gustavo Capanema. Esforço em vão, pois nas sombras da ditadura, com o Congresso Nacional fechado e quando a censura total da imprensa impedia qualquer discussão aberta e franca dos problemas nacionais, já fora decidida a liquidação do projeto de Anísio Teixeira. 
Recordo esse episódio tão-só para exemplificar porque esse livro é um texto de fundamental importância para se entender a complexidade e detalhes de grande valia do quadro político naqueles dias atormentados, em que ora vivíamos grandes esperanças e ora amargurávamos clamorosos desenganos.

\section{Dados básicos sobre Luiz}

\section{Camillo de Oliveira Netto}

- Nasceu em Itabira (Minas Gerais) no dia 9 de setembro de 1904.

- Em 1924, graduou-se em Química Industrial na Escola de Engenharia de Belo Horizonte.

- Casou-se em 1929 com Elza Malheiro de Oliveira, com quem teve dois filhos e uma filha.

- Faleceu no dia 3 de setembro de 1953, no Rio de Janeiro.

Nota

1 Relato em meu livro Herança de um sonbo - memórias de um comunista (Record, 2000, p.66).

Marco Antônio Tavares Coelho é editor executivo de ESTUDOS AVANCCADOS. É autor de Os descaminhos do São Francisco (Paz e Terra, 2005). @-macoelho@that.com.br 